\title{
A Importância do Regime de Estimativa de ISS para a Arrecadação Tributária dos Municípios Brasileiros
}

\author{
Marcos Takao Ozaki \\ Ciro Biderman
}

\begin{abstract}
Resumo
Este artigo analisa alguns aspectos do regime de estimativa na arrecadação do Imposto Sobre Serviços de Qualquer Natureza (ISS). Na primeira parte analisa-se a importância da arrecadação própria dos municípios em função das mudanças institucionais dos anos 1990, sobretudo a Constituição Federal de 1988 e a Lei de Responsabilidade Fiscal de 2000. Em seguida discute-se a importância dos serviços como fonte de arrecadação e o papel que o regime de estimativas em particular ou a simplificação administrativa em geral podem ter na cobrança deste imposto. A terceira parte do artigo apresenta três estudos de caso. Em dois deles (São Paulo e Vitória da Conquista) mostra-se como o regime de estimativa pode ajudar na arrecadação, enquanto o terceiro caso serve como contrafactual, mostrando que o regime de estimativa não é nenhuma panacéia. A última seção discute alguns aspectos legais e de finanças públicas que concernem ao ISS. Finalmente, apresentam-se algumas conclusões.
\end{abstract}

Palavras-chave: finanças públicas; setor de serviços; simplicidade administrativa.

\begin{abstract}
This paper aims to analyze the effect of a special regime of taxes, the Regime de Estimativa used on the tax on services (ISS) charged by the municipalities in Brazil. The first section analyzes the importance for municipalities to have their own tax system after the Federal Constitution (1988) and the Lei de Responsabilidade Fiscal (Fiscal Responsibility Law) (2000). In the second section the service sector is discussed and the role of the regime de estimativas as a way of simplification in the tax system. The third section presents three case studies. The first and the second case address how this regime can help the municipalities. The third case emphasizes that the simplification is an instrument to improve the tax system rather than a panacea. In the forth section some legal and public finance aspects regarding the ISS are discussed. Finaly some conclusions are drawn.
\end{abstract}

Key words: public finance; service sector; administrative simplicity. 


\section{A Evolução da Arrecadação Própria dos Municípios na DÉCADA DE 1990}

Com a Constituição de 1988 os municípios foram considerados entes federativos da União, levando-os à autonomia municipal, em termos políticos, administrativos, legislativos e financeiros. A partir desse momento receberam oficialmente a delegação de competência tributária para instituir, fiscalizar, arrecadar e administrar tributos de sua própria competência, em contraposição a uma dependência de transferência de recursos por parte da União. É claro que apenas a delegação de um direito não implica a sua execução. Como se pode observar no Gráfico 1, em 2001 no Estado de São Paulo diversos municípios dependiam consideravelmente das transferências. Na realidade, a CF/88 não acabou com as transferências, mas estabeleceu critérios para o repasse de impostos federais e estaduais para os municípios, mantendo-se uma parcela de transferências voluntárias.

\section{Gráfico 1: Composição das Receitas Orçamentárias dos Municípios}

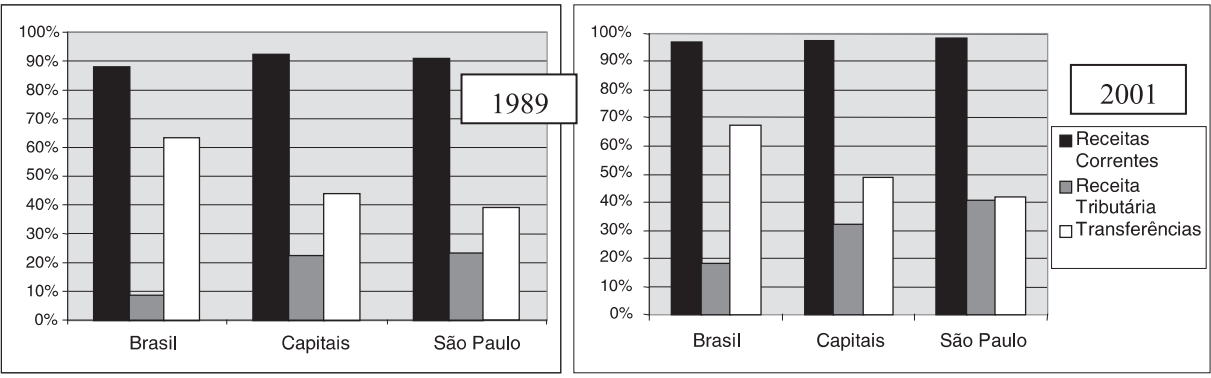

Fonte: tabulação própria a partir dos dados do STN.

Como se pode observar no Gráfico 1, as receitas tributárias aumentaram consideravelmente entre 1989 e 2001. Para o total dos municípios brasileiros a arrecadação própria representava cerca de $9 \%$ da receita orçamentária. Os municípios viviam essencialmente das transferências, que alcançavam $63 \%$ da receita. Este padrão é um pouco diferente, tomando apenas as receitas das capitais dos Estados. Para este grupo de municípios as receitas próprias atingiam 22\% do total da receita, número bem semelhante aos $23 \%$ observados no município de São Paulo (MSP). Em 2001 o quadro havia mudado consideravelmente. A participação das receitas próprias dos municípios aumentou para, respectivamente, 18\% (todos os municípios do Brasil), 32\% (capitais) e 41\% (MSP). É importante 
destacar que este aumento nas receitas próprias não se deu às custas de uma redução da proporção das receitas de transferência, como também deve estar claro no Gráfico 1. De fato, a proporção das transferências aumentou para todos os casos analisados (Brasil, Capitais e MSP). Na verdade, a diminuição relevante ocorreu nas despesas de capital, que está implícita no aumento da proporção das receitas correntes na receita total. Em 1989 as receitas de capital representavam 12\% das receitas dos municípios, reduzindo-se para 3\% em 2001. Este fato implica que análises bastante difundidas indicando que a transferência de responsabilidades por parte dos municípios não foi seguida por uma transferência de recursos precisam ser, no mínimo, requalificadas.

De qualquer maneira, se a Constituição de 1988 regulamentou a arrecadação própria dos municípios e ampliou, pelo menos potencialmente, a sua base, aumentou também os deveres dos entes locais. Adicionalmente, com a regulamentação da Lei de Responsabilidade Fiscal que entrou em vigor em maio de 2000, por meio da Lei Complementar n. 101, aumentou ainda mais a necessidade de se ampliar a base tributária própria. Com a nova lei não é mais permitido aos Estados e municípios manter déficits crônicos que acabavam sempre absorvidos pelo governo federal, como virou praxe nos anos 1990. Particularmente cabe observar o artigo 11 da referida lei:

"Art. 11. Constituem requisitos essenciais da responsabilidade na gestão fiscal a instituição, previsão e efetiva arrecadação de todos os tributos da competência constitucional do ente da federação.

Parágrafo único. É vedada a realização de transferências voluntárias para o ente que não observe o disposto no caput, no que se refere aos impostos.”

Ou seja, instituir, prever e, efetivamente, arrecadar tributos da própria competência dos municípios (ISS, ITBI, IPTU, taxas, contribuições, entre outros) é requisito essencial para ser responsável na gestão fiscal. O parágrafo único é claro ao enunciar que o ente que não observar a gestão fiscal responsável será proibido de receber transferências voluntárias. Quer dizer, a boa gestão da arrecadação própria é duplamente premiada já que o aumento de arrecadação é alavancado pelo aumento nas transferências voluntárias.

Apesar da propalada autonomia municipal, Neves (2000) afirma que houve centralização de recursos por parte do governo federal no que se refere à manutenção de competências exclusivas (art. 21) e privativas (art. 22), na atual Constituição. A vigência da Constituição Federal de 1988, para Afonso e Araújo (2000), propiciou a ocorrência de uma onda de descentralização, denominada pelos autores de municipalização. Com tal fenômeno, houve um movimento de 
municipalização da receita, aliado a um processo desordenado de descentralização de encargos.

Após a Constituição de 1988 o crescimento das receitas municipais não se deve apenas ao aumento das transferências federais e estaduais. Houve crescimento considerável das receitas próprias dos municípios. Segundo Afonso e Araújo (2000), nas grandes cidades o crescimento se dá em função da modernização fazendária e, após a estabilização econômica, pela melhoria dos sistemas de avaliação das propriedades imobiliárias e pelo crescimento dos serviços, à frente da indústria e do comércio. Nas cidades de pequeno porte e de regiões muito pobres, o aumento na arrecadação tende a ser explicado pela simples regulamentação e início de cobrança de impostos e taxas, uma vez que, uma década atrás, em diversos municípios, nada era cobrado $^{(1)}$.

O Gráfico 2 deixa claro que as receitas dos municípios cresceram a uma taxa superior à verificada para os demais entes. O crescimento real da receita municipal, nesse período de 10 anos, foi de $197 \%$ contra 55\% para a União e $64 \%$ para os Estados. Em 1988 os municípios eram responsáveis por 2,9\% do total da arrecadação. Em 1998 já tinham praticamente dobrado esta representação para $5,3 \%$.

\section{Gráfico 2: Evolução da Arrecadação da União, Estados e Municípios (1988=100)}

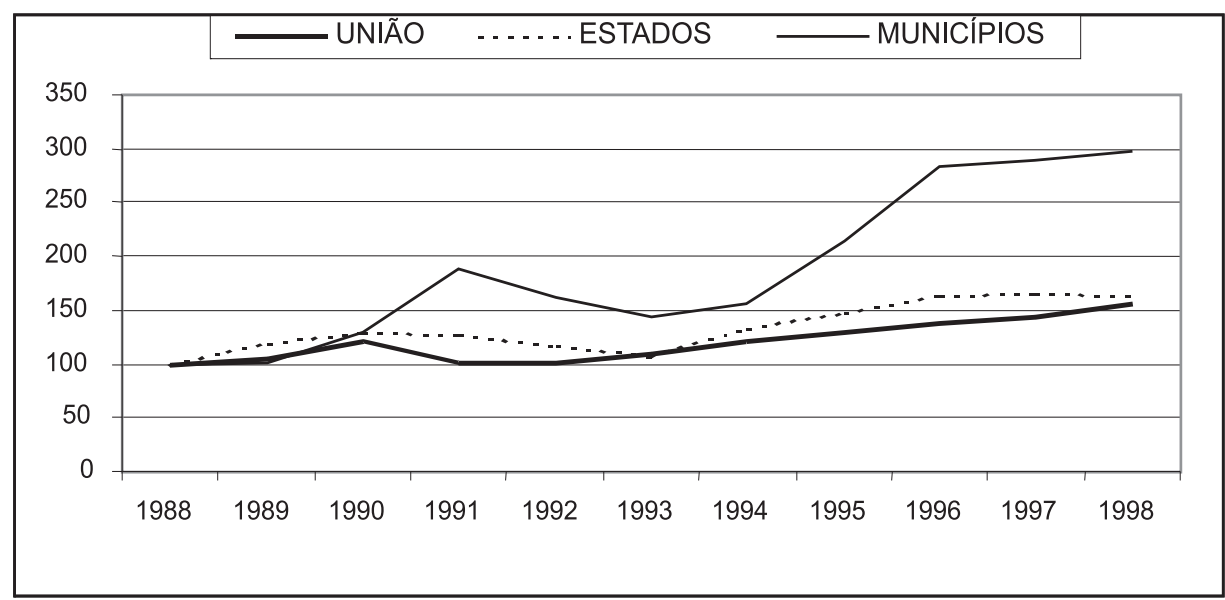

Fonte: Afonso e Araújo (2000). 
Como se pode notar na Tabela 1, em 2001 as receitas tributárias representavam quase 16 bilhões de reais, ou seja, 1,3\% do PIB daquele ano ${ }^{(2)}$. Os municípios ainda são altamente dependentes das transferências intergovernamentais que representam $69 \%$ da receita corrente. No entanto vale notar a relevância da arrecadação própria na composição da receita. A maior parte das receitas próprias (56\%) provém de impostos e estes impostos são compostos essencialmente pelo ISS (51\%) e pelo IPTU (41\%). Além do mais, nota-se que a participação das receitas próprias é bem superior nas capitais em geral, chegando a $41 \%$ no maior município do país. É importante destacar que as capitais respondem por boa parte da arrecadação tributária dos municípios brasileiros. Este fenômeno é ainda mais pronunciado quando observamos São Paulo. O município conta com pouco mais de $6 \%$ da população do país, no entanto é responsável por $23 \%$ da arrecadação própria e $27 \%$ da arrecadação de ISS da amostra considerada.

\section{Tabela 1: Composição de Receitas Selecionadas para Diferentes Agregações dos Municípios (2001)}

\begin{tabular}{|c|r|r|r|r|r|r|r|r|}
\hline \multirow{2}{*}{ Receitas } & \multicolumn{4}{|c|}{ Milhões de reais } & \multicolumn{2}{c|}{$\%$ Receita corrente } & Capitais & MSP \\
\cline { 2 - 8 } & Brasil & Capitais & \multicolumn{1}{c|}{ MSP } & Brasil & Capitais & \multicolumn{1}{c|}{ MSP } & Total & Total \\
\hline Correntes & 84.984 & 26.836 & 8.810 & $100 \%$ & $100 \%$ & $100 \%$ & $32 \%$ & $10 \%$ \\
\hline Tributárias & 15.875 & 8.884 & 3.625 & $19 \%$ & $33 \%$ & $41 \%$ & $56 \%$ & $23 \%$ \\
\hline Impostos & 13.607 & 8.053 & 3.479 & $16 \%$ & $30 \%$ & $39 \%$ & $59 \%$ & $26 \%$ \\
\hline IPTU & 5.524 & 2.969 & 1.422 & $6 \%$ & $11 \%$ & $16 \%$ & $54 \%$ & $26 \%$ \\
\hline ISS & 6.906 & 4.496 & 1.848 & $8 \%$ & $17 \%$ & $21 \%$ & $65 \%$ & $27 \%$ \\
\hline Transferências & 58.525 & 13.408 & 3.749 & $69 \%$ & $50 \%$ & $43 \%$ & $23 \%$ & $6 \%$ \\
\hline União & 28.022 & 5.365 & 656 & $33 \%$ & $20 \%$ & $7 \%$ & $19 \%$ & $2 \%$ \\
\hline FPM & 15.135 & 1.602 & 36 & $18 \%$ & $6 \%$ & $0 \%$ & $11 \%$ & $0 \%$ \\
\hline Estados & 29.397 & 7.931 & 3.092 & $35 \%$ & $30 \%$ & $35 \%$ & $27 \%$ & $11 \%$ \\
\hline
\end{tabular}

Fonte: tabulação própria a partir dos dados do STN.

A despeito do grande crescimento da receita própria municipal nos últimos anos, há ainda um grande potencial inexplorado. Há, principalmente para as cidades médias e algumas de grande porte, possibilidade de se investir em cadastramento, sistemas de controle, fiscalização, treinamento de pessoal. Segundo Afonso e Araújo (2000) trata-se de investimentos com elevadíssimo retorno, mesmo para os critérios mais rígidos de análise de investimentos.

Por outro lado, a delegação de competência tributária aos municípios, associada às transferência do governo federal e dos Estados, gerou uma multiplicação dos municípios que, de 4.189 em 1988, passaram para 5.507 em 1997. Esta lógica de multiplicação dos municípios revela uma faceta não cooperativa do federalismo brasileiro e o caráter predatório desta, em termos de redistribuição perversa de recursos financeiros e de distorção nos critérios eleitorais de representação da maioria em cada Estado (vide Abrúcio [2000]). Tal ímpeto de multiplicação começou a ser refreado com a aprovação da Emenda Constitucional n. 15 (emenda 
Jobim), que acarretou uma paralisação no processo de desmembramento dos municípios, ocorrendo a criação de apenas 53 municipalidades entre 1996 e 2000. Neste caso, a coordenação federal foi capaz de conter o modelo predatório.

\section{A Importância dos Serviços como Fonte de Arrecadação e o Regime de Estimativa}

O crescimento na participação do ISS na arrecadação dos municípios deveu-se em parte ao crescimento do peso deste setor nas atividades urbanas. Em 1999, $57 \%$ da força de trabalho estava no setor terciário (comércio e serviços). Tal setor tem crescido muito nos últimos anos, o que pode ser ilustrado pela Tabela 2. Enquanto caiu a proporção do setor primário e secundário, respectivamente, de $37 \%$ e $23 \%$ para $25 \%$ e $19 \%$, o setor dos serviços aumentou sua participação de 41\% em 1977 para 57\% em 1999.

Tabela 2: Porcentagem da PEA nos Grandes Setores de Atividade para o Brasil, as Regiões Metropolitanas e a Região Metropolitana de São Paulo (RMSP)

\begin{tabular}{|l|r|r|r|r|r|r|}
\hline \multirow{2}{*}{ Setor } & \multicolumn{3}{|c|}{1977} & \multicolumn{3}{c|}{1999} \\
\cline { 2 - 7 } & Brasil & Metrópoles & RMSP & Brasil & Metrópoles & \multicolumn{1}{c|}{ RMSP } \\
\hline Primário & $37 \%$ & $3 \%$ & $1 \%$ & $25 \%$ & $2 \%$ & $1 \%$ \\
\hline Secundário & $23 \%$ & $36 \%$ & $46 \%$ & $19 \%$ & $23 \%$ & $26 \%$ \\
\hline Terciário & $41 \%$ & $61 \%$ & $53 \%$ & $57 \%$ & $75 \%$ & $73 \%$ \\
\hline
\end{tabular}

Fonte: tabulação própria a partir dos micro-dados da PNAD de 1977 e de 1999 (Ibge).

É importante destacar que o setor terciário é ainda mais relevante, quando se consideram as regiões metropolitanas. Cumpre observar a queda pronunciada do secundário nestas regiões. A tabela destaca o caso da Região Metropolitana de São Paulo (RMSP). Para esta região, em 1977, o emprego no secundário era próximo ao emprego no terciário. Em 1999 o emprego em atividades terciárias na RMSP era praticamente 3 vezes o emprego no secundário. Dado este quadro, fica mais ou menos claro que a atividade dos serviços vem ganhando importância e que, portanto, pode representar fonte considerável de arrecadação para os entes municipais, especialmente das regiões mais populosas, onde representam três quartos da força de trabalho.

Uma das grandes dificuldades de arrecadação no setor de serviços é o seu grau de informalidade. Neste artigo discute-se como o regime de estimativa poderia configurar-se como alternativa importante para aumentar a eficiência arrecadatória. Diversos manuais de finanças públicas ${ }^{(3)}$ definem o que vem a ser um sistema 
tributário desejável. Para Stiglitz (2000), tal sistema caracteriza-se pelo seguinte elenco. 1) Eficiência econômica: não deve interferir na alocação eficiente de recursos. 2) Simplicidade administrativa: deve ser fácil e relativamente barato de se operar. 3) Flexibilidade: deve responder com agilidade, de preferência automaticamente, às mudanças econômicas. 4) Responsabilidade política: os indivíduos devem saber quanto estão pagando e recebendo (transparência). 5) Justiça: indivíduos iguais devem ser tratados da mesma forma; indivíduos diferentes, de forma diferenciada, garantindo-se que quem pode mais paga mais.

Existe um ônus administrativo do sistema tributário em vigor, no sentido de que o contribuinte, dada a complexidade da legislação tributária, contrata terceiros (advogados, contadores etc.) para ajudá-lo no planejamento tributário. A administração governamental, por seu lado, deve contratar advogados e contadores para defender os seus direitos. Tal gasto pode ser considerado peso morto, decorrente da complexidade da legislação tributária. Um sistema mais simplificado poderia reduzir o ônus administrativo, aumentando a eficiência do sistema e, portanto, beneficiando toda a sociedade.

Em geral os elementos de um sistema tributário desejável são concorrentes. Por exemplo, um ganho de eficiência, muitas vezes, é obtido em detrimento da justiça. Dada a necessidade de processo administrativo para se questionar a cobrança maior pode ser que seja mais econômico suportar o pagamento abusivo do que recorrer à justiça. Além do mais, a incidência menor dificilmente será captada pelo sistema. Em ambos os casos, o regime de estimativa não estaria respeitando a justiça na arrecadação: empresas com a mesma receita poderiam estar pagando valores diferentes, se forem de setores distintos; e empresas com receitas distintas poderiam estar pagando o mesmo imposto. Assim, existe a possibilidade de que o regime de estimativa simplesmente troque eficiência por justiça.

Segundo Martins (2000), “a estimativa é uma antevisão daquilo que será devido, uma forma de antecipação do imposto devido, principalmente quando não é possível estabelecer exatamente quanto é o valor do imposto. Todavia, se o imposto realmente devido for inferior à estimativa, teremos pagamento de imposto a maior, que deverá ser devolvido ou compensado pelo fisco. Se o imposto for pago a menor em função da estimativa feita, há necessidade de o contribuinte pagar a diferença”. Este princípio não será aplicado na prática, se o custo de exigí-lo for maior do que o benefício, como foi discutido no parágrafo anterior.

Estimativa não se confunde com parcelamento, porque aí o imposto já está apurado e é devido. O imposto apenas não foi pago, mas o crédito tributário já foi constituído. Na estimativa, o imposto foi avaliado para certo período, obtendo-se um valor maior ou menor em relação ao efetivamente devido; mas o crédito tributário ainda não foi constituído. Corresponde a uma antecipação do imposto. 
A estimativa só poderá ser utilizada quando não existirem dados reais aferidos pelo município e para as atividades de serviços, para as quais não é possível aferir com exatidão qual é o imposto devido. Utiliza-se um valor estimado, que deve ser verificado no final de certo período, para confirmar se o imposto foi recolhido corretamente. Se há diferença a pagar ou a ser restituída, deveria proceder-se ao débito ou crédito tributário. Segundo Borges e Reis (1994), no município do Rio de Janeiro, o regime de estimativa do ISS é aplicado nas seguintes situações:

- Atividade exercida em caráter provisório, entendendo-se por caráter provisório as atividades cujo exercício seja de natureza temporária e estejam vinculadas a fatores ou acontecimentos ocasionais ou excepcionais.

. Contribuinte de rudimentar organização.

- Contribuinte sem condições de emitir documentos fiscais ou deixar de cumprir com regularidade as obrigações acessórias previstas na legislação.

- Contribuinte ou grupo de contribuintes cuja espécie, modalidade ou volume de negócios ou atividades aconselhem, a exclusivo critério da autoridade competente, tratamento fiscal específico.

Esta definição não difere muito da aplicada no município de São Paulo. Grosso modo, as principais atividades de serviços passíveis de serem enquadradas em regime de estimativa são: hotéis; motéis; oficinas mecânicas; serviços de assistência técnica, como conserto de geladeiras, aparelhos de informática, eletrodomésticos, entre outros; serviços de diversões públicas, como bingos, boates, cabarés, casas de videokês; estacionamentos; e vídeo-locadoras.

Caso o movimento econômico do contribuinte, durante o ano, tenha sido maior do que a receita estimada no mesmo período, o contribuinte terá de pagar uma décima terceira parcela no final do ano referente ao saldo devedor de imposto. Se, caso contrário, o contribuinte tiver um faturamento no ano menor do que a receita anual estimada, poderá requerer restituição de saldo credor de ISS. Outros entes políticos também utilizam o regime de estimativa: a União, no IRPJ, e vários Estados para a cobrança do ICMS. Nada impede que o regime de estimativa seja aplicado sobre os demais tributos municipais (IPTU, ITBI, etc.).

\section{Breves Estudos de Caso}

\section{O Município de São Paulo}

Em São Paulo, o regime de estimativa foi criado no início da década de 80, pelo 
Prof. Henrique Fingermann, da EAESP-FGV. Algumas atividades de serviços não eram sujeitas à incidência do ISS, devido à dificuldade em se determinar se o contribuinte emitia notas fiscais corretamente ao prestar os serviços. Os setores mais sujeitos a este tipo de problema incluem hotéis, motéis, oficinas mecânicas, atividades de assistência técnica, vídeo-locadoras, estacionamentos, entre outros. Havia, inicialmente, uma equipe de três pessoas na subinspetoria de arrecadação por estimativa. Atualmente há cerca de vinte. A arrecadação de ISS tem contribuído para a arrecadação tributária do município com uma participação de 2 a 3\% da arrecadação total, segundo informações do setor de estimativa da Secretaria Municipal das Finanças. As atividades de serviços que mais têm contribuído para arrecadar ISS no regime de estimativa, com base no ano 2000, são: estacionamentos (33,50\%), hospedagem em motéis (14,72\%); assistência técnica (12,53\%); cabeleireiros (7,18\%) e hospedagem em hotéis (5,89\%).

Caso o faturamento do contribuinte tenha sido maior do que o faturamento estimado, este poderá requerer restituição do saldo credor, mediante processo administrativo. A compensação de valores só está prevista para o exercício em vigência. Por exemplo, pode-se compensar valores pagos a maior em março de 2002 no mês de abril de 2002. Com relação a exercícios passados, procedimentos administrativos internos impedem que haja compensação de valores. O contribuinte, não concordando com a receita mensal estimada, poderá requerer a sua revisão, também por meio de processo administrativo. A prefeitura de São Paulo optou, portanto, por dificultar a revisão da estimativa, assumindo a priori que o custo administrativo de ajuste seria maior do que seu benefício.

A estimativa pode ser definida com base na aplicação de um índice de valor agregado (margem de lucro) sobre as despesas informadas. Cada atividade sujeita ao regime de estimativa possui uma margem própria definida, por exemplo, por meio da receita apurada nos últimos doze meses pelo contribuinte. Outra forma de definir a receita mensal estimada é a constatação feita in loco pelo plantão fiscal. O Judiciário considera o regime de estimativa como constitucional, conforme Martins (2000), apesar de não se caracterizar a ocorrência de um fato gerador que enseje a cobrança do ISS.

Um dos problemas que o setor de estimativa paulistano tem enfrentado é o desenquadramento de parte da base de contribuintes, com enquadramento no SIMPLES federal. Empresas cadastradas no SIMPLES estão sujeita à alíquota geral de ISS de $1 \%$ ao mês sobre o faturamento, ao invés de $5 \%$ pela estimativa. Há alguns critérios a serem observados para que o desenquadramento se efetive como, por exemplo, não possuir filial em outro município e apresentar documentação da Secretaria da Receita Federal atualizada, comprobatória de sua condição de SIMPLES-ME. De qualquer maneira, não resta dúvida de que, para o município de 
São Paulo, tanto o regime de estimativa como o SIMPLES-ME contribuem para a simplificação administrativa, melhorando a eficiência do sistema.

\section{Vitória da Conquista, BA}

Outra experiência interessante em relação ao regime de estimativa para o lançamento do ISS ocorre na cidade de Vitória da Conquista, relatada por Barboza (2000). Situado a 328 km de Salvador, com população de quase 250 mil habitantes, o município estava passando por dificuldades financeiras, decorrentes de fatores que têm afligido a grande maioria dos municípios brasileiros, tais como o fim do financiamento inflacionário, a instituição do Fundo de Estabilização Fiscal (FEF) e a diminuição da atividade econômica, com o paralelo aumento das demandas sociais e da responsabilidade municipal na oferta de serviços públicos. Há também algumas características específicas que contribuíram para gerar ou agravar a crise financeira de Vitória da Conquista, tais como o clientelismo, a utilização de recursos públicos em benefício de pequenos grupos e o descaso com a arrecadação de impostos.

Em 1997, a administração municipal adotou diversas medidas para enfrentar seus problemas financeiros, atuando em três frentes: a) elevação de receitas; b) controle e racionalização de despesas e c) ampliação da participação popular nas decisões relativas a investimentos públicos, promovendo a publicização do Estado, com aumento da transparência. No que tange à elevação das receitas, uma das iniciativas mais importantes foi a instituição da cobrança de ISS por estimativa.

O regime de cobrança de ISS por estimativa em Vitória da Conquista incentivou a emissão de notas fiscais e ampliou a base tributária, com a incorporação de contribuintes que tenderiam à informalidade. Aliado a tais fatos, o êxito do regime de arrecadação deveu-se também a mudanças no sistema de pontuação, no qual se baseia a remuneração variável dos fiscais. O salário variável passou a ser composto com base no número de visitas realizadas e no número de autos de infração efetivamente pagos: autos lavrados não são pontuados. A prefeitura investiu na fiscalização, realizando concursos para auditores fiscais e modernizando suas instalações, além de atualizar seu parque de informática com recursos do PMAT, programa de modernização da arrecadação tributária, criado pelo BNDES.

Cumpre lembrar que outras medidas, que não constituem apenas a efetiva fiscalização do ISS, foram tomadas pela administração municipal de Vitória da Conquista: redução da multa de mora, de 30 para 5\%; alongamento do prazo de parcelamento dos débitos fiscais de 24 para 50 meses; realização de ampla campanha para pagamento do IPTU, usando-se a mídia impressa e eletrônica local; concessão de anistia de 50\% para os débitos fiscais anteriores a 1997; 
extinção da progressividade no tempo para terrenos não murados e sua substituição por uma alíquota maior de IPTU. Em 1998, a arrecadação de ISS do município baiano subiu de R \$ 2,2 milhões para R \$ 3,4 milhões.

Além disso, Vitória da Conquista, por força de sua agilidade em obter recursos e graças à recuperação de sua saúde financeira, conseguiu celebrar diversos convênios com o governo federal, que injetaram mais verbas no município e possibilitaram a criação de diversos programas na área social. A arrecadação total aumentou de $\mathrm{R}$ \$ 30,4 milhões em 1996 para R \$ 41,9 milhões em 1998. Isso proporcionou regularização do pagamento a funcionários, fornecedores e credores.

\section{Tupandi, RS}

Tupandi fica a 90 km da capital do Rio Grande do Sul. Segundo Klering (1997), por mais de um século a comunidade do município permaneceu em situação de total marasmo e de dificuldades regionais e nacionais para alcançar níveis superiores de produção e de qualidade de vida. Possui 2.500 habitantes, numa área de 61 $\mathrm{km}^{2}$; sua economia é centrada na agricultura, com concentração de minifúndios. O pequeno produtor rural tendia a repetir o processo de produção convencional aprendido pelos seus antepassados, em processo pouco racional e produtivo, sendo, portanto, pouco econômico e lucrativo. A conseqüência era a fuga dos jovens da cidade, em busca de trabalho em municípios vizinhos ou na periferia das grandes cidades.

Em 1993, foi criado o FUNDAT - Fundo de Desenvolvimento Agropecuário do Município de Tupandi, por iniciativa do poder executivo do município, com o objetivo principal de tornar produtivas as propriedades de minifúndios, normalmente apenas de subsistência. De forma secundária, objetivava fixar o homem no campo, criar expectativa de melhoria da qualidade de vida na agropecuária, viabilizar economicamente a pequena propriedade rural, absorver a mão-de-obra disponível, aumentar a arrecadação de ICMS e criar mão-de-obra especializada.

Em termos de resultado, houve aumento de ICMS que, de um índice de retorno de 0,035218 passou para 0,075541 . Tal aumento compensou o investimento feito pela prefeitura. Em termos vivenciais, proporcionou novo ânimo à vida das pessoas, que se tornaram mais alegres, confiantes e solidárias. Pelas características da região, o ponto forte da economia local é a circulação de mercadorias, em que há incidência de ICMS. Klering não menciona se Tupandi também obteve aumento de arrecadação de ISS. Na verdade, a idéia de descrever tal caso era mostrar que a arrecadação do ISS, em geral, e o regime de estimativa em particular não constituem panacéia. Conforme o perfil do município, outros fatores podem ser mais relevantes para a retomada do seu crescimento. 


\section{Demais Aspectos Econômicos, de Finanças Públicas e Legais DO ISS}

O Imposto sobre Serviços de Qualquer Natureza - ISS - pertence à competência dos Municípios (CF/88, art. 156, III, com a redação da EC n 3/93) e do Distrito Federal (CF/88, art. 147). É competência de lei complementar: (a) a fixação das alíquotas máximas do imposto e (b) a exclusão de seu campo de incidência de exportações de serviços para o Exterior (CF/88, art. 156, §3º I I e II). Respeitadas a Constituição Federal e as leis complementares pertinentes, os Municípios acham-se dotados de competência privativa que lhes permite legislar acerca do ISS no respectivo território por meio de lei ordinária.

Martins (2000) define serviço como o resultado da atividade humana na criação de um bem que não se apresente sob a forma de bem material. Tal conceito envolve a prestação de fazer, conforme dita a teoria do direito civil referente às obrigações. Dado que se trata de bem imaterial e intangível, dificulta a arrecadação.

O ISS incide sobre serviços de qualquer natureza, excetuados os que se sujeitam ao ICMS: prestações de serviços de transporte interestadual e intermunicipal e de comunicação. Por determinação da Magna Carta de 1988 (art. 156, III), cabe à lei complementar definir serviços para efeito de incidência do imposto municipal. Os serviços abrangidos pelo ISS constam da Lista de Serviços detalhados no artigo $8^{\circ}$ do Decreto-lei $n^{\circ}$ 406/68 - Redação dada pela Lei Complementar no 56 de 15/12/87 e Lei Complementar n ${ }^{\circ} 100$, de 22/12/1999. Fazem parte da lista serviços relacionados à saúde, diversões públicas, profissionais liberais, construção civil, serviços financeiros, entre outros num total de 101 serviços dos mais variados tipos.

O fato gerador se caracteriza pela prestação de serviços praticada por empresa ou por profissional autônomo. As características do aspecto material, segundo Haddad (1998) são: efetiva prestação do serviço; autonomia no exercício da atividade; finalidade lucrativa; irrelevância de que o prestador tenha ou não estabelecimento fixo; imposto devido independentemente de o contribuinte cumprir exigências legais, regulamentares ou administrativas, atinentes à atividade exercida.

Com relação ao aspecto pessoal do fato gerador, há o sujeito ativo e o sujeito passivo. O sujeito ativo é o ente político tributante, ou seja, os municípios ou o Distrito Federal. O sujeito passivo, que paga o tributo, pode ser: a) a empresa, isto é, a pessoa jurídica que pratica as atividades tributáveis; b) o profissional autônomo que exerce as atividades tributáveis em nome próprio ou sem vínculo empregatício e c) o responsável tributário. O parágrafo único do artigo 10 do Decreto-lei no 406/68 estabelece que não são contribuintes as pessoas que prestem serviços em relação de emprego, os trabalhadores avulsos, os diretores e membros de conselhos 
consultivo ou fiscal de sociedades. Também não são autônomos os trabalhadores avulsos tais como estivadores e conferentes e os prestadores de serviços de natureza eventual a diversas empresas ou sob a dependência delas.

Os serviços sujeitos à estimativa estão concentrados em bens de luxo, como estacionamentos, hotéis ou casas de diversão: cerca de $60 \%$ da arrecadação por estimativa do município de São Paulo. Em princípio este tipo de serviço representa uma parcela maior da renda dos mais ricos. Se este for o caso, considerando que estes setores seriam subtaxados não fosse o regime de estimativa, pode-se considerar o regime de estimativa como progressivo. É verdade que outros serviços relevantes no regime de estimativa para o ISS paulistano como cabeleireiros ou assistência técnica podem eventualmente representar parcela maior da renda da faixa mais pobre da população. Verificar se o regime de estimativa contribui para reduzir a regressividade usual de um imposto sobre o consumo foge do escopo deste artigo; no entanto tudo leva a crer que seu efeito é no mínimo neutro, se considerarmos que $60 \%$ da arrecadação está concentrada em lazer.

Há três casos no município de São Paulo que contribuem para a progressividade do ISS em geral: (a) alíquotas menores do que 5\% para microempresas e empresas de pequeno porte que fazem parte do SIMPLES federal, supostamente com menor capacidade de pagamento do que as empresas médias e grandes; (b) alíquotas diferenciadas (10\% e não os usuais 5\%) cobradas de atividades de serviços relacionadas a diversões públicas (cobrada em regime de estimativa na maioria dos casos); (c) isenções da cobrança de ISS de determinadas atividades de serviços tais, como serviços prestados por ambulantes e sapateiros remendões, entre outros.

No que concerne ao aspecto espacial do fato gerador, em regra o ISS é devido ao município onde se situa o estabelecimento prestador do serviço, caso de empresa ou profissional autônomo estabelecido; ou o domicílio do prestador do serviço, caso de ambulante. Como exceção, o ISS é devido ao município onde se efetuar a prestação de serviço, quando se tratar de atividade de construção civil. No caso de empresas que exploram serviços de pedágio, o local da prestação é o município em cujo território haja parcela da estrada explorada. (Alínea c da Lei Complementar $n^{\circ}$ 100/99). Existe jurisprudência no STJ, definindo que, para qualquer tipo de serviço, a incidência se dará na municipalidade, onde o serviço foi prestado e não mais no município-sede da empresa. Se esta decisão fosse adotada de fato, poderia alterar completamente o quadro de guerra fiscal entre os municípios pela arrecadação de ISS. Na prática, no entanto, é muito difícil rastrear a efetiva prestação do serviço.

A base de cálculo, via de regra, é o preço integral do serviço. Vale destacar as exceções. Na prestação de serviços pela construção civil deve-se efetuar a dedução da base de cálculo das parcelas referentes aos materiais fornecidos 
pelo prestador do serviço e pelas subempreitadas já tributadas pelo ISS. Profissionais liberais são tributados por taxa fixa, independentemente do preço dos serviços prestados. Finalmente, na exploração de rodovia ou ponte, mediante a cobrança de pedágio dos usuários, o ISS é calculado sobre a parcela do preço correspondente à proporção do município na extensão da rodovia ou metade da extensão da ponte que una dois municípios.

\section{Notas Conclusivas}

A Constituição Federal de 1988 deu aos municípios o status de ente federativo, o que envolve apresentar autonomia financeira e tributária. Neste esforço de arrecadação tributária, o ISS apresenta posição de destaque, pois o setor de serviços é um dos que mais cresceu na década passada. Isto se reflete nas estatísticas de arrecadação tributária municipal que mostram que o ISS é a maior fonte de arrecadação dos municípios, à frente dos impostos patrimoniais como o IPTU. Investir na implementação legal e administrativa do ISS pode, portanto, trazer grandes benefícios aos municípios. Mais do isso, investir em formas de arrecadação alternativas, que levem a maior simplicidade administrativa e à eficiência econômica é tudo o que se deseja de um sistema tributário.

O regime de estimativa de ISS é uma técnica de arrecadação tributária que acarreta efetivo incremento à sua arrecadação. Cobra-se o imposto sobre atividades que, caso não fossem enquadradas em estimativa, dificilmente recolheriam o tributo com base em seu movimento econômico. Trata-se de aperfeiçoamento na forma de arrecadação de determinados setores, sendo aplicável tanto para os grandes municípios (São Paulo), quanto para médios (Vitória da Conquista).

O caso de São Paulo ilustra que o regime de estimativa garante a um sistema tributário mais simplificado. Pelo seu período de existência e pela sua estrutura, pode ser considerado como referência para os demais municípios brasileiros. No caso de Vitória da Conquista (BA), um município de pequeno porte, a implantação do regime de estimativa, entre outras ações, possibilitou a criação de um círculo virtuoso de desenvolvimento econômico. O município recuperou sua saúde financeira, o que possibilitou a celebração de convênios com o governo federal, injetando mais verbas no município e possibilitando a criação de vários programas na área social.

Por fim, ressalta-se que investir em arrecadação tributária própria pode trazer retornos consideráveis, especialmente se considerarmos o efeito multiplicador, via transferências extras da União ou dos Estados, conforme ocorreu com Vitória da Conquista (BA). Em particular, a criatividade na forma de arrecadação pode ser 
elemento fundamental na estratégia de arrecadação dos municípios. Uma das desvantagens dos municípios na arrecadação de tributos é a guerra fiscal predatória discutida anteriormente; porém uma das vantagens é que o sistema pode adaptarse com mais flexibilidade aos seus contribuintes correntes e em perspectiva. $\mathrm{O}$ desenho mais flexível pode permitir que o município arrecade de maneira mais eficiente ou mais justa em função de suas peculiaridades. O regime de estimativas ou o SIMPLES-ME são sistemas que trazem empresas do mercado informal para o mercado formal, reduzindo custos administrativos para as prefeituras e para os contribuintes. É ferramenta que deve ser utilizada no planejamento municipal. Neste sentido, o desenquadramento de uma série de empresas do SIMPLES, promovida pelo governo federal recentemente, pode significar um passo na direção errada.

\title{
Notas
}

\begin{abstract}
${ }^{1}$ Observando a amostra do STN em 1989 composta por 4246 municípios (fora os da capital), 806 (ou seja, 19\%) não acusavam a cobrança de ISS enquanto 537 (13\%) não acusavam a cobrança de IPTU. Em 2001 apenas 23 municípios não recolhiam ISS e 212 não recolhiam IPTU representando, respectivamente, $0,5 \%$ e $4,3 \%$ da amostra de 4884 municípios neste ano.

${ }^{2}$ Na realidade em termos relativos este valor já foi mais alto. Como registram Afonso e Araújo (2000), em 1998 a receita própria dos municípios de mais de R 14 bilhões representava 1,6\% do PIB.

${ }^{3}$ Vide, inter alia, Stiglitz (2000), Musgrave (1980) e, para uma versão mais sucinta, Mankiw (1999).
\end{abstract}

Artigo recebido em 05.11.2003. Aprovado em 15.03.2004.

\section{Bibliografia}

ABRÚCIO, F.L.

Os laços federativos brasileiros: avanços, obstáculos e dilemas no processo de coordenação intergovernamental. 2000. $277 \mathrm{f}$. Tese (Doutorado em Ciência Política). USP, São Paulo.
AFONSO, J.R. R.; ARAÚJO, E. A.

A capacidade de gastos dos municípios brasileiros: arrecadação própria e receita disponível. In Cadernos Adenauer 4: Os municípios e as eleições de 2000. São Paulo: Fundação Konrad-AdenauerStiftung, jun. 2000. p. 35-57. 
BORGES, J. C.

ISS no município do Rio de Janeiro. Rio de Janeiro: Esplanada ADCOAS, 1994.

FARAH, M. F. S.;

BARBOSA, H. B.

Novas experiências de gestão pública e cidadania. Rio de Janeiro: Fundação Getúlio Vargas, 2000.

\section{HADDAD, R.}

Legislação do ISS - município de São Paulo. São Paulo: Pró-concurso, 1998. Apostila.

HYMAN, D. N.

Public Finance - a contemporary application of theory to policy. Fifth edition, Orlando, FL, EUA: The Dryden Press - Harcout Brace College Publishers, 1999.

JUNIOR, A. V. et alii.

Lei de responsabilidade fiscal comentada: lei complementar n. 101, de 4 de maio de 2000. 2. ed., São Paulo: Atlas, 2001.

KEEN, M.;

MARCHAND, $\mathrm{M}$.

Fiscal competition and the pattern of public spending. Journal of Public Economics, Amsterdam, Holland: North-Holland. v. 66, n. 1, 1997.

\section{LEMGRUBER,A.V.}

Problemas e oportunidades na repartição das receitas: competição, harmonização e coordenação na área fiscal. Brasília: SRF/MF, 1999.
MANKIW, N. G.

Introdução à economia. 4. ed., São Paulo: Ed. Campus, 1999.

MARTINS, S. P.

Manual do imposto sobre serviços, 3 . Ed., São Paulo: Atlas, 2000.

MUSGRAVE, R.A.;

MUSGRAVE, $P$.

Finanças públicas teoria e prática. São Paulo: Campus, 1980.

NEVES, G. H. et alii.

Os municípios e as eleições de 2000.

In Cadernos Adenauer 4: Os municípios e as eleições de 2000. São Paulo: Fundação Konrad-AdenauerStiftung, jun. 2000.

REZENDE, F.

Finanças públicas. 2. ed. São Paulo: Atlas, 2001.

SPINK, P.;

CLEMENTE, R.

(Org.) 20 experiências de gestão pública e cidadania. Rio de Janeiro:

Getúlio Vargas, 1997.

STIGLITZ, J. E.

Economics of the Public Sector. Third Edition, New York: W. W. Norton \& Company, Inc., 2000. 